\title{
Confusa e irritante multidão de livros: relações entre o contexto histórico-informacional da Europa Moderna e a estrutura documentária de Bibliotheca Universalis, de Conrad Gesner
}

\author{
Confusing and annoying crowd of books: relations between the historical and informational \\ context of modern Europe and the Bibliotheca Universalis of Conrad Gesner
}

Andre Vieira de Freitas Araujo

Doutorando do Programa de Pós-Graduação em Ciência da Informação da Escola de Comunicação e Artes da Universidade de São Paulo - ECA/USP. Bolsista da Coordenação de Aperfeiçoamento de Pessoal de Nível

Superior - CAPES.

Professor do Curso de Biblioteconomia e Gestão de Unidades de Informação da Faculdade de Administração e Ciências Contábeis da Universidade Federal do Rio de Janeiro - UFRJ.

E-mail: armarius.araujo@gmail.com

\begin{abstract}
Giulia Crippa
Livre Docente em Ciência da Informação pela Faculdade de Filosofia, Ciências e Letras de Ribeirão Preto -

FFCLRP/USP.

Professora do curso de Biblioteconomia e Ciências da Informação e da Documentação da FFCLRP/USP.

E-mail: giuliac@ffclrp.usp.br
\end{abstract}

\section{Resumo}

A Imprensa teve como um dos seus mais significativos impactos a vasta, intensa e acelerada produção de bibliografias, como meios de registro, organização, seleção, disponibilização e mediação de documentos. Entre as inúmeras conseqüências da Imprensa está a necessidade de se operar a chamada explosão informacional fenômeno investigado, do ponto de vista histórico-cultural, por autores como Peter Burke e Ann Blair. A partir desta paisagem, o artigo busca estabelecer relações entre o contexto histórico-informacional da Europa Moderna e Bibliotheca Universalis, de Conrad Gesner (Séc. XVI). Bibliotheca arrola aspectos da cultura manuscrita e impressa e traz implicitamente uma profunda reflexão descritiva e semântica sobre os documentos e os saberes, conforme se evidencia nos estudos de Alfredo Serrai e Fiammetta Sabba. O "gesto bibliográfico" gesneriano é mais do que uma resposta a confusa et noxia illa librorum multitude ("confusa e irritante multidão de livros", que hoje nos remete ao sentido da denominada information overload): é a força que arquiteta a própria Bibliografia enquanto disciplina.

Palavras Chave: Bibliografia. Bibliotheca Universalis (1545). Conrad Gesner (1516-1565). Gesto bibliográfico. Imprensa. Pandectae (1548-1549).

\begin{abstract}
Printing Press had, as one of their most significant impacts, the vast, intense and accelerated production of bibliographies, as means of recording, organizing, selecting, availability and mediation of documents. One of the many consequences of Printing Press is the need to operate the so-called information explosion - a phenomenon investigated from an historical and cultural point of view by authors such as Peter Burke and Ann Blair. Based on this frame, this article seeks to establish relations between the historical and informational context of Modern Europe and the Bibliotheca Universalis, written by Conrad Gesner (16th century). The Bibliotheca enrolls aspects of manuscript and printed culture and implicitly brings a deep descriptive and semantic reflection on documents and knowledge, as evidenced in studies of Alfredo Serrai and Fiammetta Sabba. The "bibliographic gesture" of Gesner is more than just a response to the confusa et noxia illa librorum multitudo ("confusing and annoying crowd of books"), which in our days brings us to the meaning of the so-called information overload: it is the force that builds the very architecture of Bibliography as a discipline.
\end{abstract}

Keywords: Bibliographic gesture. Bibliography. Bibliotheca Universalis (1545). Conrad Gesner (1516-1565). Pandectae (1548-1549). Printing Press.

InCID: R. Ci. Inf. e Doc., Ribeirão Preto, v. 7, n. esp., p. 224-241, ago. 2016.

DOI: 10.11606/issn.2178-2075.v7iespp224-241 


\section{Introdução}

Neste artigo, pretendemos estabelecer, como o próprio título já indica, relações entre o contexto histórico-informacional da Europa Moderna e a obra Bibliotheca Universalis, de Conrad Gesner, publicada no Séc. XVI.

Para tanto, faremos inicialmente alguns comentários entre a relação da Impressa com a chamada explosão informacional - tema largamente investigado, sobretudo do ponto de vista histórico-cultural, por autores como Ann Blair, Peter Burke, entre outros. Procuraremos observar algo que chamaremos de "ressonância" desse momento histórico tão fundamental que é a chamada revolução informacional: em que medida essa esfera, essa paisagem histórico-cultural teria tido um alcance na própria estrutura documentária de Bibliotheca Universalis, de Conrad Gesner, do Séc. XVI. Em relação à obra de Gesner, trata-se de uma discussão pautada, principalmente, nos estudos realizados pelos especialistas Gesnerianos Alfredo Serrai e Fiammetta Sabba.

É necessário, para entendermos a proposta do estudo, uma contextualização inicial que não pretende ser historiografia do livro e da biblioteca, mas uma introdução para os que não conhecem bem o período e o universo em questão, pois é importante lembrar o papel assumido pela Imprensa, principalmente em relação à sua constituição com caracteres móveis.

\section{A Imprensa e a revolução informacional}

A Imprensa e a invenção de caracteres móveis não foi, contrariamente ao que comumente se pensa, uma invenção de Gutenberg, que limitou-se a aperfeiçoar técnicas e ferramentas bem presentes na Europa do Séc. XV. Sua verdadeira invenção foi a de abrir o caminho para grande imprensa. A invenção da impressão com tipos móveis representa a síntese de um conjunto de invenções anteriores.

Sabe-se pouco sobre Gutenberg. Em princípio, teve uma formação como ourives, trabalhando com metais maleáveis. Ele nada mais fez do que uma associação entre tecnologias e conhecimentos que circulavam ao longo da história para, em seguida, devido à sua habilidade técnica e comercial, se associar a Johann Fust e a Peter Schöfer, com os quais deu início a grande aventura da impressão em ampla escala. A xilogravura, por exemplo, já era uma técnica em uso havia muitos anos.

InCID: R. Ci. Inf. e Doc., Ribeirão Preto, v. 7, n. esp., p. 224-241, ago. 2016. 
Gutenberg, portanto, se apropriou de um conjunto de conhecimentos já acumulados naquele período, graças a sua boa formação com os metais. Teve, assim, a ideia de constituir aqueles que passaram a ser chamados de caracteres móveis, recurso maleável e dinâmico de produção e reprodução de textos.

O que são os caracteres tipográficos? Trata-se de palavras compostas de unidades, chamadas “tipos”, que pré existem, como unidades, às palavras. Caracteres móveis já existiam na China, mas se tratava de pictografias, e as páginas impressas que deles resultavam aproximam-se mais do conceito de gravura, pois a cada pictograma corresponde um conceito, tornando a mobilidade restrita. Antes da primeira metade do Séc. XV também as áreas da Coréia e da Turquia se dotam de instrumentos próximos daqueles para a reprodução textual, mas a unidade das palavras continua limitando a mobilidade dos tipos.

A grande inovação atribuída a Gutenberg consistiu em separar, nos tipos, as unidades alfabéticas, tornando as palavras um produto, podendo, assim, reutilizar as unidades independentemente do resultado final. Walter Ong (1998) considera isso não só como um elemento de ruptura psicológica na relação com o produto, mas também como um primeiro exemplo ante litteram da linha de montagem, vista como uma série de etapas fixas que produz objetos complexos idênticos, compostos de partes substituíveis. Nesse caso, o produto é o livro impresso. Teremos que esperar até meados do século XVIII para que esse processo se aplique a outras manufaturas.

Entre Estrasburgo e Mogúncia, Gutenberg (FIG. 1) realizou suas atividades, aperfeiçoando técnicas antigas e introduzindo novidades. A Bíblia de 42 linhas, publicada em 3 anos, de 1452 até 1455, é testemunha da eficiência técnica por ele alcançada, nos procedimentos de produção dos punções, das matrizes e da fusão dos caracteres, praticamente inalterados até o Séc. XIX. 


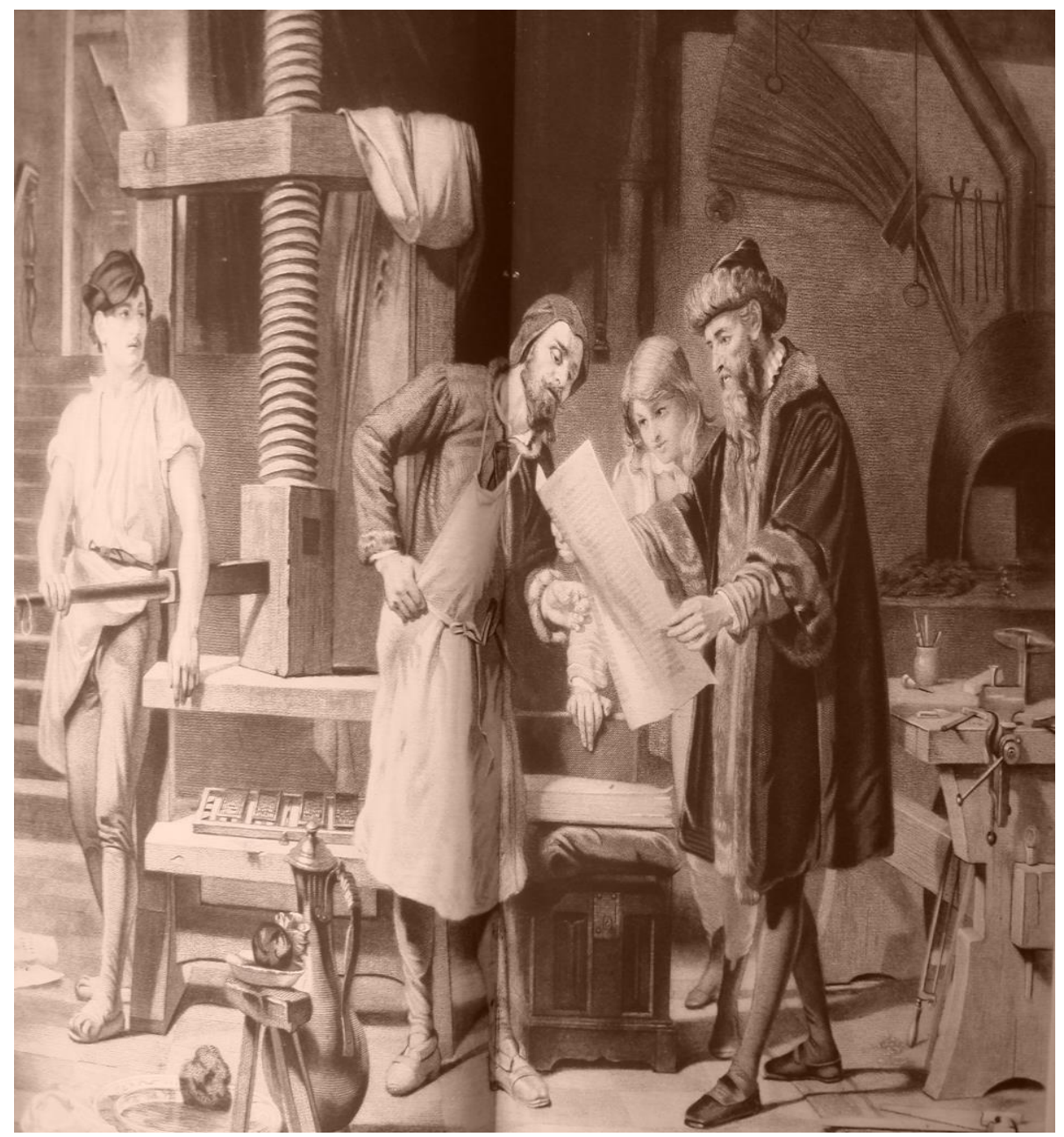

FIGURA 1 - Gutenberg e a Tipografia

Gutenberg faz sua primeira prova tipográfica. Heliogravura da antiga estampa gravada por Aug. Ledoux, impressa por Alfred Chardon e editada por Dusacq em Paris.

Fonte: ICONOGRAPHIE de l'imprimerie et du livre. Bulletin officiel des maitres imprimeurs, France, dez. 1927. Supplément.

Sua Imprensa Tipográfica, além de dar grande difusão ao livro, teve outros reflexos menos conhecidos, mas não por isso menos relevantes: sabe-se que foi graças a Imprensa que documentos outros, ditos "efêmeros", se disseminaram amplamente. Aliás, foram esses documentos que, em um primeiro momento, foram produzidos em larga escala, para só em um segundo momento se voltar a tecnologia para a produção de livros.

A difusão da Imprensa Tipográfica de Gutenberg representa uma aceleração progressiva do número de livros disponíveis que, nos dois séculos anteriores, já tinha se ampliado. Ainda que os efeitos na organização bibliotecária demoraram quase um século desde a invenção para se tornarem evidentes, não há dúvida de que o interesse para esses materiais despertou mudanças culturais profundas ocorreram na Europa, no momento em que a reprodução dos livros passou progressivamente dos scriptoria para as oficinas dos 
impressores.

É interessante observar como o manuscrito, documento reservado a poucos, repleto de sacralidade, tornou-se "profano" justamente pela técnica que permitia a reprodução praticamente infinita dos textos, pelas tiragens progressivamente maiores, e pode ser observado o surgimento de espaços para outros sentidos e significados ao livro:

No momento de sua descoberta, a ars artificialiter scribendi (arte de se escrever artificialmente) molda-se rigorosamente pelo manuscrito. Mas o livro impresso ganha progressivamente feições próprias à medida que os impressores se familiarizam com a nova técnica" (GILMONT, 1999, p. 47-48).

No momento em que essa arte de se escrever artificialmente surge, observam-se os impactos que isso traz, principalmente no contexto Eclesiástico, pois

A descoberta de Gutenberg modificou as condições do movimento de ideias acelerando a circulação dos textos e reduzindo o custo de cada cópia. No entanto, não convém exagerar o impacto imediato que essa invenção teve sobre uma sociedade ainda amplamente analfabeta" (GILMONT, 1999, p. 47-48).

Por um longo período, a Imprensa gerou, com efeito, um ambiente cultural de incerteza extrema: a revolução provocada pelos caracteres móveis, como todas as revoluções, encontrou seus oponentes. Desde o fim da Idade Média assistia-se a uma diminuição na qualidade exterior dos livros, devido à expansão da formação universitária que veio gerar, desde o séc. XIII, uma maior procura do material de leitura. Os custos de produção puderam ser consideravelmente reduzidos pela utilização do papel ao invés do pergaminho, desde meados do Séc. XV.

Hoje em dia tende-se a considerar que o crescimento do número de leitores e o aumento do nível de educação determinaram o contexto que permitiu a invenção da impressão tipográfica de livros, enquanto o enorme aumento das tiragens permitiu uma propagação de informação e conhecimentos até então desconhecidos, que abriu caminho às ideias "democráticas", já que a educação deixou de ser privilégio de uma pequena elite para se tornar, em princípio, acessível a todas as pessoas.

Esta tendência, todavia, representava um perigo para autores conservadores que, embora estivessem abertos às ideias humanistas, continuavam a apoiar o tradicional sistema feudal de valores. Estudos estatísticos mostram que no começo do século XVI o interesse pela leitura cresceu consideravelmente entre vastas camadas da população. Não só surgiram novos títulos no mercado, como também aumentou com rapidez o nível de produção das obras 
literárias. Esta evolução acompanhou a crescente tendência de secularização e a redução da oferta de escritos de caráter religioso que dominara até então.

Este processo de transformação produziu inseguranças em teólogos de orientação conservadora, em humanistas e artistas que passaram a considerar os livros como material inútil e um luxo supérfluo. A quem afirmasse que os livros eram registros permanentes e imutáveis da experiência e dos conhecimentos humanos, era recordado o seu caráter efêmero. Enquanto a população duplicou entre 1500 e 1600, a produção de livros cresceu, em média, dez vezes na Europa.

O resultado de uma reunião entre bibliotecários de mosteiros europeus, principalmente beneditinos, ocorrida na Alemanha em torno de 1475, destacou questões relativas aos livros impressos e às possíveis mudanças que as bibliotecas de manuscritos iriam sofrer, principalmente levando em conta a paisagem cultural do âmbito monástico: a produção textual era um meio e um recurso de dialogo com Deus. Como ficaria, então essa relação que, até então, era extremamente orgânica e que agora passava a ser um recurso tecnológico? Um monge presente nesta reunião registrou a seguinte nota:

Martin de Melk disse que ela [a Imprensa] era trabalho do demônio, que destruiria a arte do scriptorium, que faz o homem ocioso e o conduz para tentação, além de corroer lentamente a autoridade da Igreja". O monge de Melk ainda complementou que: "[...] os produtos desta nova arte eram coisas profanas, pois não foram criados sob o controle da Igreja (TRAUE, 1991, p. 66).

Alguns monges, embora não tão favoráveis, pareciam mais tolerantes:

Gabriel de Windesheim disse que era muito tarde, pois aqueles que não tem piedade ocuparam a batalha. Os custos do metal e papel eram tão alto que a "impressoria" moveria o corpo do mosteiro. Mas a Igreja tinha de aceitar que isso foi de Deus e atentar para uso de novos livros para Sua glória (TRAUE, 1991, p. 67).

Embora aceitasse este "novo livro", Gabriel de Windesheim considerou que o manuscrito sempre seria o centrum da biblioteca, ainda que o livro artificial poderia torna-se "transcendente" ou "hiperfísico", em função de seu valor e por poder existir em muitas cópias.

Basicamente, a grande questão se resumia à uma preocupação principal: em que medida o grande monopólio que se constituíra ao longo de séculos era alterado por essa nova dinâmica de produção textual. Isso é só uma pequena nota para entendermos um pouco os impactos da Imprensa dentro dos espaços e dos dispositivos informacionais existentes, mas é interessante para começarmos a desvendar um pouco a ideia de uma explosão informacional, 
que poderíamos, em termos relativos, comparar ao conceito contemporâneo de information overload, isto é: excesso de informação, que alguns estudiosos, historiadores de livros e bibliotecas, trazem e tentam aplicar ao período da chamada Europa Moderna.

\section{Explosão informacional e práticas bibliográficas}

A incorporação da nobreza e dos laicos na cultura do livro e sua posse, até então reservada aos monges, clérigos, estudantes episcopais e universitários é um fenômeno de suma importância observado por Calende Diaz (1996), que leva à abertura de um novo mercado livreiro e de novos canais de disseminação do livro, sempre lembrando que a ideia de disseminação é dimensionada a um público muito específico, enquanto letrado, particularmente interessado à aquisição, leitura, estudo e conhecimento de obras de autores gregos e romanos, e igualmente por escritos da Antiguidade.

Outro aspecto ligado diretamente à disseminação do livro na Europa Moderna foi a prática da bibliofilia no Séc. XVI, que, junto com a produção manuscrita, constituiu coleções orgânicas de textos de acordo com cada gosto.

Assim, durante o Séc. XVI, ainda que persistisse o predomínio de livros religiosos, se publicavam também livros laicos, como gramáticas, dicionários, livros técnicos de botânica, zoologia, anatomia, medicina, matemática, autores clássicos e outros (CALENDE DIAZ, 1996).

Para Peter Burke (2003), ao examinar a construção do saber nos tempos modernos, verifica-se que a variedade de conhecimentos gera uma distinção entre categorias: teoria e prática, filosofia e empirismo, ciência e arte e, paralelamente ao conhecimento científico e ao saber produzido nas universidades e círculos intelectuais, a produção para o grande público também se intensifica.

O mesmo autor, em seu texto clássico “Os problemas causados por Gutenberg” (BURKE, 2002), ilustra as metáforas que surgem nesse período em relação à alta produção textual, em contraposição à escassez medieval de livros, metáforas e analogias que revelam a experiência de intelectuais que interpretam o fenômeno da impressão como superfluidade textual: todo esse espaço, essa cosmologia informacional é descrito como labirinto, como floresta, oceano, e uma série de outros termos que evocam a ideia de um lugar hostil e 
Andre Vieira de Freitas Araujo e Giulia Crippa

perigoso, reveladoras da insurgência do problema do acesso e dos critérios a serem adotados para a seleção e a recuperação dos documentos. Para Burke (2002),

Os estudiosos, ou mais genericamente os que buscassem o conhecimento, também
enfrentavam problemas. Observemos deste ponto de vista a assim-chamada
"explosão" da informação - uma metáfora desconfortável que faz lembrar a pólvora -
subsequente à invenção da imprensa. A informação se alastrou "em quantidades
nunca vistas e numa velocidade inaudita". Alguns estudiosos logo notaram as
desvantagens do novo sistema. O astrônomo humanista Johann Regiomontanus
observou, por volta de 1464 , que os tipógrafos negligentes multiplicariam os erros.
Outro humanista, Niccolò Perotti, propôs em 1470 um projeto defendendo a censura
erudita. Mais sério ainda era o problema da preservação da informação e, ligado a
isso, o da seleção e crítica de livros e autores. Em outras palavras, a nova invenção
produziu uma necessidade de novos métodos de gerenciamento da informação.

Robert Burton (2005), em 1621 escreve, em sua "Anatomy of Melancholy", que "Já temos um enorme caos e uma confusão de livros. Estamos subjugados por eles, doem-nos os olhos de ler e os dedos de passar as folhas”. (BURTON, 2005, p. 66).

Avançando mais um pouco em nossas reflexões, e endossando as realizações anteriores à Modernidade, vale a pena lembrar de obras como a de Calímaco, na Antiguidade, ou de Cassiodoro, na Idade Media, para refletirmos sobre a ideia de um gesto bibliográfico como realização consciente de seleção e indicação de textos hierarquicamente descritos, que se fundaria nesses autores bem anteriores à época que estamos tratando.

Com efeito, a construção de elencos, de listas, de registros selecionados e organizados remete a uma tradição bem presente na era manuscrita, constituindo algo que poderíamos identificar como atividades proto-bibliográficas. Nesse sentido consideramos relevantes os dois autores citados acima, respectivamente: Calímaco (350 - c.240 d.C) e Cassiodoro (Séc. $\mathrm{VI})$.

O primeiro compilou o Pinakes, que pode ser equiparado a uma bibliografia, na medida em que considera tanto o aspecto intelectual bem como o conteúdo formal dos documentos citados.

Por sua vez Cassiodoro pode ser considerado um dos principais bibliógrafos da Idade Média (CAPACCIONI, 2006).

Em seu Institutiones divinarum et saecularium litterarum (Instituições das literaturas divinas e seculares), além de estabelecer as tarefas que cabiam aos monges no âmbito de sua biblioteca, Vivarium, Cassiodoro apontou em detalhes os livros necessários à sua formação, bem como à formação específica dos cristãos. Influenciado pelo escasso peso que o autor teve 
na formulação propriamente teológica da Idade Média, seu tratado acabou sendo pouco reconhecido e observado em relação à autoridade que teve na constituição das bibliotecas medievais, na medida em que propôs uma concepção especificamente cristã às bibliotecas e, principalmente, por ter integrado ao núcleo religioso uma parte considerável de autores pagãos, além de influenciar as práticas de leitura e dos leitores, indicando, de maneira específica, as modalidades e as partes de cada um dos textos selecionados.

De fato, Cassiodoro compilou algo que pode ser identificado claramente como bibliografia: na primeira parte de Institutiones ele trata dos autores cristãos, dos comentaristas e daqueles autores que, ainda que cristãos, devem ser aproximados com cautela por conter elementos heréticos. Na segunda parte, definindo as sete artes liberais, trata dos livros correspondentes a cada arte, incluindo uma farta quantidade de autores da latinidade clássica (RICHÉ, 2000; CRIPPA, 2015). Cassiodoro desenvolveu um trabalho gigantesco, dedicandose a operações não somente de ordem descritiva e seletiva, mas também de como poderia ser realizada uma abordagem - para utilizar uma terminologia contemporânea - temática dos documentos selecionados.

É ingênuo, portanto, imaginar uma Antiguidade e uma Idade Média que desconhecem princípios de organização e representação da informação e do conhecimento. O que, na realidade, precisa considerar é que eles refletem interesses diversos daqueles que se observam na formação da Europa Moderna que, propondo bases científicas para o conhecimento, busca uma sistemática bibliográfica.

É por isso que, quando se considera uma História da Bibliografia, se colocam como primeiras reflexões sobre a disciplina as produções que tiveram início na era da tipografia, que coincide com a insurgência das personalidades humanistas, voltadas ao estudo de textos antigos. A coincidência entre a visão humanista e a invenção da impressão tipográfica, com a consequente explosão informacional, obriga os intelectuais a desenhar formas de organização dos materiais e, ao lado do interesse pela classificação dos seres, na base da busca científica, muitos se dedicaram também à organização dos saberes.

Não é por acaso que os bibliógrafos modernos revelam uma atitude ligada às habilidades que a nascente prática anatômica proporcionava: ao lado da dissecação de corpos humanos e animais, se busca a dissecação do conhecimento, originando a estrutura de uma anatomia do conhecimento que encontra nas práticas bibliográficas a sua expressão e mesmo materialização (ARAUJO, 2015). 
Nesta direção destaca-se o Liber de scriptoribus ecclesiasticis (1494), de autoria de Johannes Trithemius (1462-1516), que foi o primeiro repertório biobibliográfico da Idade Moderna que, embora tenha esse título, não se limita às obras de escritores eclesiásticos no sentido estrito mas, no âmbito da civilização cristã, incorpora escritos filosóficos, científicos e literários (SERRAI, 1997).

Inúmeros bibliógrafos espalham-se pela Europa não só preocupados com a “ordem dos livros", mas também com a representação do conhecimento por meio de bibliografias e catálogos (CHARTIER, 1998). Neste momento, na Europa do início da era moderna, destacase o interesse para taxonomia em estudiosos humanistas, como é o caso de Conrad Gesner.

O que nos interessa desse fenômeno da explosão informacional da Modernidade, provocada pela impressão, é a ideia de uma sobrecarga de informação, não somente como fenômeno social, mas também psicológico, na medida em que essa quantidade de informação se torna excessiva de tal forma que destrava uma série de sentimentos dos quais podemos destacar o medo, a opressão a falta de significado e a irritação, destacando essa última, pois será diretamente relacionada com o trabalho de Gesner.

\section{Uma multidão de livros}

De acordo com Ann Blair (2010, p. 55), “[...] as referências à abundância de livros apareceu bem antes do início do período moderno, quer favoravelmente (como abundância cornucópia) ou desfavoravelmente (como superabundância). Dada a rápida acumulação de material impresso no Séc. XVI, a multitudo librorum foi trilhada como uma questão de experiência geral [...] e foi invocada em apoio a uma variedade de argumentos [...]".

Portanto, no Séc. XVI, o tema da multidão de livros passa a ser muito evidente e se espelha diretamente na produção de diversos tipos de documentos: livros sobre livros, livros que discutem livros, que exaltam livros, que anunciam amor aos livros e livros que tentam discutir como devem ser organizados e apresentados os livros, como revisões, catálogos e enciclopédias. Obviamente, essas tipologias documentárias que incluem catálogos e enciclopédias não são fenômenos inerentes à Europa Moderna, pois já se encontram em épocas anteriores. Todavia, essa é uma época em que se busca uma sistemática bibliográfica, e essa é o grande diferencial que podemos observar. 
No que toca nosso interesse, bastante particular, do universo bibliotecário e biblioteconômico, cada vez mais nesse período se tem uma noção aprofundada de um projeto universalista, de biblioteca e de bibliografias universais, fonte da qual Gesner bebe diretamente. É uma época em que o bibliotecário é visto como figura que deve ter grande formação intelectual.

Se, de um lado,

\begin{abstract}
A existência de livros impressos facilitou mais do que nunca a tarefa de encontrar informações - desde que antes se encontrasse o livro certo. Para isso, foi preciso compilar catálogos para grandes bibliotecas, particulares ou públicas. Baillet compilou um catálogo em 32 volumes para seu patrão, o magistrado Lamoignon, um trabalho que ajuda a explicar seu desabafo, como já mencionado, sobre o advento de uma época de barbárie. A compilação desses catálogos criou o problema de como organizá-los. Por assunto ou por autor numa lista em ordem alfabética? Se por assunto, segundo o tradicional currículo das universidades ou de um modo novo e mais adequado às novas descobertas (um problema que, entre outros, preocupava Leibniz)? (BOTTASSO, 1984, p. 97).
\end{abstract}

Do outro

Também existia o problema do acesso. Como poderiam os leitores descobrir que livros estavam disponíveis numa determinada biblioteca? Como particularmente poderiam os leitores de outras cidades ou países saber que valeria a pena empreender uma viagem para uma determinada biblioteca em busca de um determinado livro? Imprimiram-se alguns catálogos, como o da Bodleian Library de Oxford do início do século XVII. Uma alternativa ao catálogo de determinada biblioteca era uma bibliografia impressa, o catálogo de uma biblioteca ideal ou da "biblioteca sem paredes" (como a chama Chartier, adaptando uma expressão de André Malraux)" (GUALDONI, 2008, p. 63).

Onde se insere, então, o projeto Gesneriano nessa problemática da explosão informacional da Modernidade, da multidão dos livros? Se insere diretamente porque Gesner, humanista, polímata do Séc. XVI não somente se ocupa de uma série de áreas do conhecimento enquanto disciplinas, como a medicina, a linguística, a teologia, a botânica, a zoologia, a paleontologia e a mineralogia, mas também se ocupa (sobretudo na maturidade) da produção de obras bibliográficas, nas quais ele tenta elencar, listar, determinados conhecimentos específicos. De fato, o que precede sua grande obra bibliográfica, Bibliotheca Universalis, é um catálogo de plantas.

InCID: R. Ci. Inf. e Doc., Ribeirão Preto, v. 7, n. esp., p. 224-241, ago. 2016. 


\section{Gesner, Bibliotheca Universalis e as Pandectae}

É no contexto cultural que tentamos esboçar que, dos primeiros anos da Europa Moderna, vive e trabalha o "pai da Bibliografia" e fundador da disciplina bibliográfica, Conrad Gesner (1516-1564).

Gesner nasceu em Zurique em 16 de março 1516, e seu aniversário de 500 anos de nascimento vem sendo comemorado na Europa com várias iniciativas ${ }^{1}$. Seus pais eram pobres e foi só com a ajuda de seu tio materno que iniciou seus estudos em 1521. Em 1529 passou a estudar grego e latim.

De todos os membros do grande círculo de humanistas suíços na primeira metade do Séc. XVI, a poucos podem ser atribuídas obras de valor duradouro em tantos campos de investigação como Conrad Gesner.

Gesner possuía uma insaciável sede de conhecimento, enriquecida por uma educação humanista clássica: estes dois elementos são fundamentais para compreendermos o seu papel na organização do conhecimento. E isto se reflete no número de campos em que ele publicou.

A biografia de Gesner pode ser entendida a partir de dois momentos: período de formação e período de produção científica, onde se insere a produção de obras bibliográficas, cujo maior destaque é Bibliotheca Universalis (SABBA, 2012).

Bibliotheca foi publicada em quatro partes, entre 1545-1555: 1) Bibliotheca Universalis, sive Catalogus omnium scriptorum locupletissimus, in tribus linguis, Latina, Graeca, et Hebraica [...] (1545); 2) Pandectarum sive partitionum universalium [...] (1548); 3) Partitiones theologicae (1549) e 4) Appendix bibliothecae (1555).

Bibliotheca Universalis (FIG. 2) é um catálogo alfabético-nominal, constituído por obras em latim, grego e hebraico. Está organizado pelo primeiro nome de autor e apresenta

\footnotetext{
${ }^{1}$ Para sua memória, diversos eventos tem ocorrido em 2016, em Zurique: 1) Exposição no Museu Nacional (em colaboração com a Biblioteca Central de Zurique); 2) Exposição no Museu de Zoologia da Universidade de Zurique, 3) Exposição no Jardim Zoológico de Zurique; 4) Exposição Gessner no Antigo Jardim Botânico de Zurique; 5) Exposição no Jardim Sukkulenten e 6) Congresso Internacional Conrad Gessner (de 06 a 09 de junho). Este congresso reuniu especialistas e estudiosos Gesnerianos, evidenciando a multiplicidade disciplinar e de interesses do polímata suíço. Este evento contou com nossa participação, com a palestra: "Conrad Gessner in the tropics: the presence of Bibliotheca Universalis and Pandectae in two Brazilian heritages libraries". Esta intervenção resultará em um capítulo que fará parte do livro comemorativo a Conrad Gesner, a ser publicado em Zurique, em 2017. Para informações gerais sobre os eventos comemorativos de 2016, ver: http://www.gessner500.ch/ .
} 
extrato e resumo dos documentos listados. Se trata de um prontuário representativo do patrimônio literário da cultura ocidental.

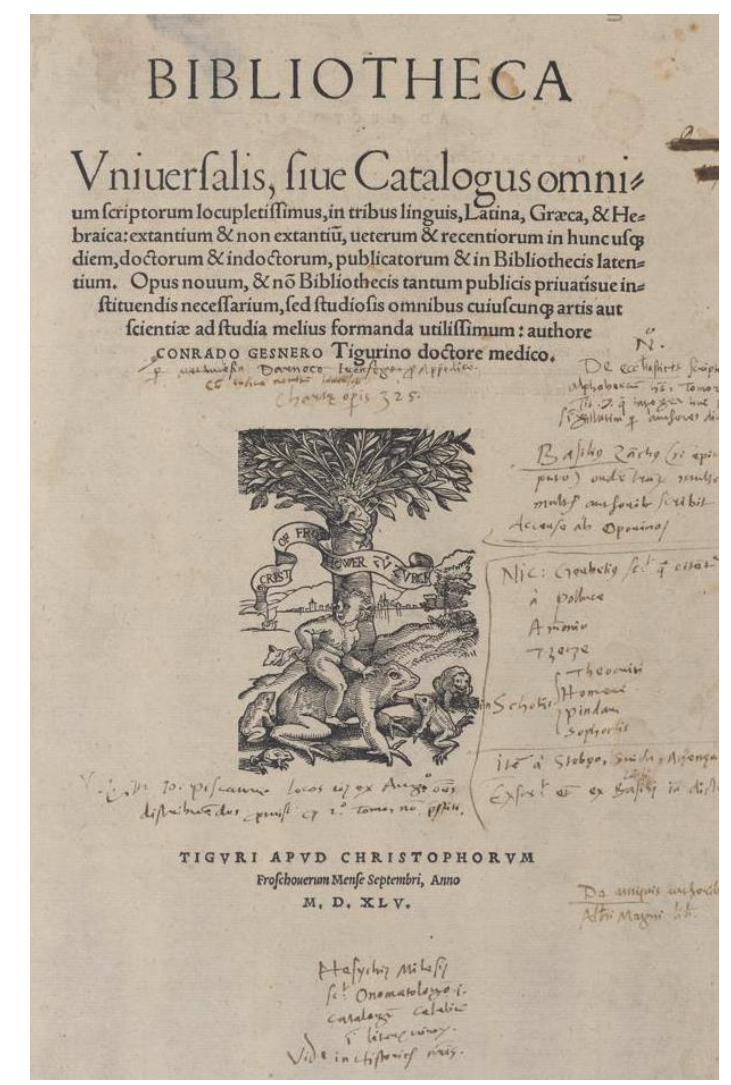

FIGURA 2 - Bibliotheca Universalis

Disponível em: <http://www.e-rara.ch/zuz/content/pageview/5079514>

De acordo com Alfredo Serrai e Fiammetta Sabba (2005), Bibliotheca apresenta descrições muitas vezes analíticas, acompanhadas por dados relevantes do lugar de impressão, editor, data e consistência do volume.

Na segunda parte, as Pandectae (FIG. 3), Gesner propõe o que seria uma estruturação semântica dos documentos elencados na primeira parte, resultando em um esquema completo não somente de todas as classes dos saberes e disciplinas, mas na ampliação do sistema de classificação medieval que até então era utilizado (ARAUJO; CRIPPA, 2015). 


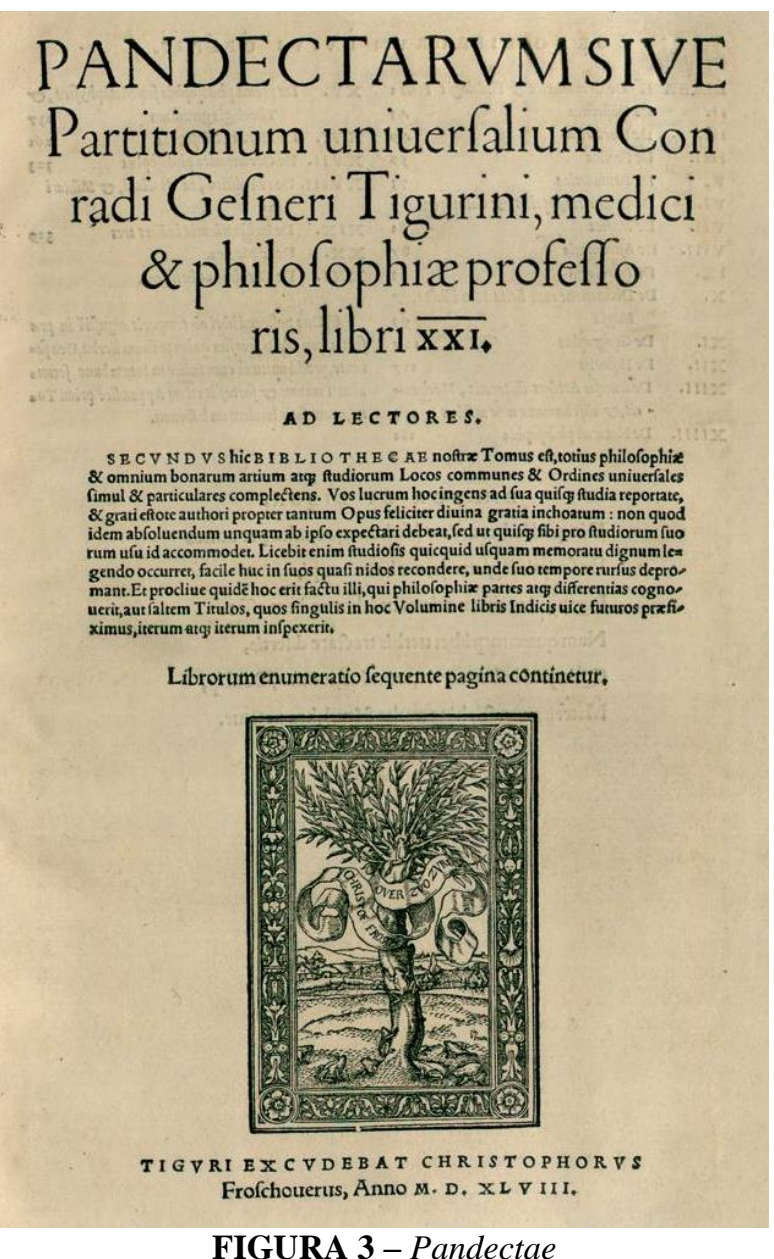

Disponível em: <http://www.e-rara.ch/zuz/content/pageview/624960>

Gesner elabora as Pandectae a partir da divisão: 1-Gramática (e Filologia), 2Dialética, 3-Retórica, 4-Poética, 5-Aritmética, 6-Geometria, 7-Música e 8-Astronomia. Estas são seguidos pelas ciências incluindo o currículo universitário medieval: 9-Astrologia, 10Adivinhação e Magia, 11-Geografia, 12-História, 13-Artes Mecânicas, 14-Filosofia Natural, 15-Metafísica, 16-Filosofia Moral, 17-Filosofia Econômica, 18-Política; e finalmente, 19Direito, 20-Medicina e 21-Teologia.

O sistema de classificação em Pandectae tem origem nas sete artes liberais e é ampliado a partir das categorias de assuntos complementares e de interesse aos estudiosos e eruditos do Renascimento.

Segundo Alfredo Serrai e Fiammetta Sabba (2005, p. 42),

Pandectae oferece notícias das obras ou das suas partes, refletindo o inteiro mundo disciplinar - com exceção da Medicina ainda inédita - que de tal modo figura enquadrado ou categorizado, e assim repertoriável e consultável, por meio de um enorme e capilar retículo de assunto". 
Cada classe de Pandectae representa um livro que corresponde a uma partição. Cada livro possui a seguinte organização: título do livro (associado ao nome da respectiva partição), a quem o livro é dedicado e a exposição geral das subclasses subordinadas à classe que nomeia o livro ou partição (ARAUJO; CRIPPA, 2015).

De acordo com Alfredo Serrai \& Fiammetta Sabba (2005, 56-57):

\begin{abstract}
As Partições, ou classes principais são articuladas em Títulos; os Títulos estão subdivididos em Partes; e estas em Seguimentos. As Partes contêm os Loci, seguidos de uma brevíssima referência aos autores e às obras que trataram, há pouco, dos temas que se identificam ou se colocam naqueles Loci. As referências são acompanhadas com indicações concernentes ao livro e ao capítulo da obra, mas que aparece muitas vezes implícita e mencionada apenas sob o nome do autor. $\mathrm{O}$ Loci são apresentados, geralmente, em sequencia temática, ou seja cobrem o arco dos argumentos que competem a uma certa parte; muitas vezes, no entanto - a exemplo, em enumerações envolvendo filósofos, animais, plantas, deuses, oráculos etc. - o Loci aparecem em ordem alfabética.
\end{abstract}

Em síntese: os livros elencados em Bibliotheca Universalis estão dispostos em ordem alfabética de seus autores e, nas Pandectae, os livros elencados estão ordenados segundo os seus assuntos, a partir dos Loci.

O sistema de Gesner evidencia sua sensibilidade classificatória, que é aplicada e teorizada com maestria. Realiza o escaneamento disciplinar com vistas a situar as obras listadas em Bibliotheca e Pandectae dentro de um conjunto mais amplo e mesmo caótico de produção e mediação documentária.

\title{
Bibliotheca Universalis e a multidão de livros
}

Aqui cabe uma retomada do assunto já tratado: o tema "multidão de livros" era de admiração e ansiedade para os autores que refletiram sobre a condição acadêmica no Séc. XVI. De modo que no prefácio de Bibliotheca Universalis Conrad Gesner queixou-se da confusa et noxia illa librorum multitude (“confusa e irritante multidão de livros") (GESNER, 1545). O sentimento de irritação fazia, então, parte da figura de Gesner e esta teria sido uma de sua motivações para se dedicar a este grandioso projeto bibliográfico de organização do conhecimento.

A percepção de uma superabundância de livros alimentou a produção de muitos outros livros destinados a sanar o problema, como vimos: bibliografias, resenhas, dicionários e enciclopédias. Gesner, como erudito e humanista qual ele era, para Capaccioni (2006), vivia 
imerso na realidade editorial de seu tempo, colaborando com impressores e tipógrafos e visitando bibliotecas; fez justamente uma imersão no que se produziu na época e nos períodos anteriores, preocupando-se, basicamente, com duas grandes "chaves", que poderíamos denominar uma de "mediação bibliográfica", ou seja, a bibliografia enquanto dispositivo mediador, e outra de bibliografia enquanto estrutura documentária, como documento de memória.

A perspectiva de mediação pode ser observada na medida em que Gesner foi o primeiro bibliógrafo da Europa Moderna a ter uma preocupação tanto com os livros em si bem como com o seu uso. Para ele, a elaboração de bibliografias era uma atividade essencial e que se impõe por si mesma (MALCLÈS, 1960).

Gesner também cunhou a expressão "a ordem dos livros" (ordo librorum) - adotada por Roger Chartier como título de um de seus trabalhos - que demonstra a sua preocupação com o sentido de ordem.

Mais que uma ordem de livros, o que alguns contemporâneos percebiam era uma "desordem de livros" que precisava ser controlada. Este é certamente um problema com que nós também estamos brigando atualmente, com a mídia eletrônica (BURKE, 2002).

\section{Considerações finais}

A Imprensa teve como um dos seus mais significativos impactos a vasta, intensa e acelerada produção de bibliografias, como meios de registro, organização, seleção, disponibilização e mediação de documentos. Entre as inúmeras consequências da Imprensa está a necessidade de se operar a chamada explosão informacional.

Com Bibliotheca Universalis e Pandectae, Conrad Gesner materializou e criou a bibliografia mais importante do início da Europa Moderna, uma vez que esta nasceu com uma proposta universalista. Por outro lado, a própria Imprensa potencializou a percepção da fisicalidade do livro, caracterizado por "detalhes bibliográficos" não presentes nos livros manuscritos.

O projeto bibliográfico Gesneriano, focado tanto nos aspectos descritivos quanto nos aspectos semânticos dos documentos, buscou oferecer recursos para que o leitor pudesse avaliar, localizar e selecionar a informação. Neste sentido, se mostrou como um dispositivo 
fundamental à crítica e validação documentária, dado o contexto histórico-informacional da Europa Moderna, demarcado pelo excesso e superabundância informacional.

Mesmo sendo crítico em relação à superabundância, Gesner exultava-se com esta, buscando a exaustividade em sua acumulação tanto de temas e obras, no qual outros poderiam escolher de acordo com seu julgamento e interesses (BLAIR, 2010).

O "gesto bibliográfico gesneriano" é mais do que uma resposta a confusa et noxia illa librorum multitude (“confusa e irritante multidão de livros") - marcada pela information overload: é a força que delineia a Bibliografia enquanto disciplina.

\section{Referências}

ARAUJO, A. V. F. Pioneirismo bibliográfico em um polímeta do séc. XVI: Conrad Gesner. Informação \& Informação, Londrina, v. 20, n. 2, maio/ago. 2015. Disponível em: <http://www.uel.br/revistas/uel/index.php/informacao/article/view/23127>. Acesso em: 15 ago. 2015

.; CRIPPA, G. A dimensão histórico-epistemológica da Organização do Conhecimento: contributos da taxonomia gesneriana, séc. XVI. In: GUIMARÃES, J. A.; DODEBEI, V. (Org.). Organização do conhecimento e diversidade cultural. Marília: ISKO-Brasil ; FUNDEPE, 2015, v. 3, p. 37-46. (Estudos Avançados em Organização do Conhecimento, v. 3). Disponível em: <http://isko-brasil.org.br/wpcontent/uploads/2015/09/Organização-do-Conhecimento-e-Diversidade-Cultural-ISKOBRASIL- 2015.pdf>. Acesso em: 10 nov. 2015.

BLAIR, A. Too much to know: managing scholarly Information before the modern age. Nem Heaven \& London: Yale University Press, 2010.

BOTTASSO, E. Storia della biblioteca in Itália. Milano: Bibliografiaca, 1984.

BURKE, P. Uma história social do conhecimento: de Gutenberg a Diderot. Rio de Janeiro: Jorge Zahar, 2003.

Problemas causados por Gutenberg: a explosão da informação nos primórdios da Europa moderna. Estudos Avançados, v. 16, n. 44, p.173-185, jan./abr. 2002.

BURTON, R. Anatomie de la Melancolie. Paris: Gallimard, 2005.

CALENDE DIAZ, J. C. Las bibliotecas de los humanistas y el Renacimiento. Revista General de Información y Documentación, v. 6, n. 2, 1996.

CAPACCIONI, A. Mapas y memorias: apostillas a una historia de la Bibliografia. Documentación de las Ciencias de la Información, Madrid, v. 29, p. 09-24, 2006. 
CHARTIER, R. A ordem dos livros: leitores, autores e bibliotecas na Europa entre os Séculos XIV e XVIII. 2. ed. Brasília: UnB, 1998. 111 p.

CRIPPA, G. Cassiodoro e as Institutiones Divinarum Litterarum como fonte histórica para a discussão sobre práticas bibliográficas e organização do conhecimento. Informação \& Informação, Londrina, v. 20, n. 2, p. 86 - 117, maio/ago. 2015. Disponível em: <http://www.uel.br/revistas/uel/index.php/informacao/article/view/23126>. Acesso em: 10 fev. 2016.

GESNER, C. Bibliotheca universalis, sive, Catalogus omnium scriptorum locupletissimus in tribus linguis Latina, Graeca \& Hebraica: extantium \& non extantium, veterum \& recentiorum in hunc usque diem, doctorum \& indoctorum, publicatorum \& in bibliothecis latentium: opus novum \& non bibliothecis tantum publicis privatisue instituendis necessarium, sed studiosis omnibus cuiuscunque artis aut scientiae ad studia melius formanda utilissimum / authore Conrado Gesnero Tigurino doctore medico. Tiguri: apud Christophorum Froschouerum, mense Septembri, anno 1545. Disponível em: <http://www.erara.ch/zuz/content/pageview/624960>. Acesso em: 20 fev. 2015.

GILMONT, J. F. Reformas protestantes e a leitura. In: CAVALLO, G.; CHARTIER, R. (Org.). História da leitura no mundo ocidental II. São Paulo: Ática, 1999. Cap. 8, p. 47-77.

GUALDONI, F. Una storia del libro. Milano: Skira, 2008.

MALCLÈS, L. N. La bibliografía. Buenos Aires: EUDEBA, 1960.

ONG, W. Oralidade e cultura escrita. Campinas: Papirus, 1998.

RICHÉ, P. As bibliotecas e a formação da cultura medieval. In: BARATIN, M.; JACOB, C. (Org.). O poder das bibliotecas: a memória dos livros no Ocidente. Rio de Janeiro: Editora, 2000. pt. 3, p. 246-256.

SABBA, F. La 'Bibliotheca Universalis' di Conrad Gesner: monumento della cultura europea. Roma: Bulzoni, 2012.

SERRAI, A. Johannes Trithemius. In: Storia della bibliografia VII: storia e critica della Catalogazione Bibliografica. Roma: Bulzoni, 1997. v. 7, p. 51-59.

.; SABBA, F. Profilo di Storia della Bibliografia. Milano: Sylvestre Bonnard, 2005.

TRAUE, J. E. (Trad.). Account of a convention of monastic librarians, ca 1475. Australian Library Journal, v. 40, n. 1, p. 65-69, feb. 1991. 